\title{
Current Limitation Method for $V / f$ Control of Five-Phase Induction Machines
}

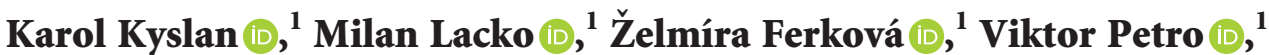 \\ Sanjeevikumar Padmanaban $\mathbb{D}^{2},{ }^{2}$ and Daniela Perduková $\mathbb{D}^{1}$ \\ ${ }^{1}$ Department of Electrical Engineering and Mechatronics, Technical University of Košice, 04200 Košice, Slovakia \\ ${ }^{2}$ CTIF Global Capsule (CGC) Laboratory, Department of Business Development and Technology, Aarhus University, \\ 7400 Herning, Denmark
}

Correspondence should be addressed to Karol Kyslan; karol.kyslan@tuke.sk

Received 6 October 2021; Accepted 20 December 2021; Published 31 January 2022

Academic Editor: Youssef Errami

Copyright (C) 2022 Karol Kyslan et al. This is an open access article distributed under the Creative Commons Attribution License, which permits unrestricted use, distribution, and reproduction in any medium, provided the original work is properly cited.

Five-phase induction machines (5pIMs) are a viable alternative for a wide range of industrial applications. The penetration of drives with 5pIM into industrial applications is slow because of the complexity of the proposed control algorithms. In standard $V / f$ control of induction machines, the stator current is not controlled directly and options for current limitation are restricted. This paper hence addresses a novel current limitation technique for the $V / f$ control algorithm of 5pIM. In addition, a simple speed sensorless control algorithm based on the slip compensation is introduced. A combination of both algorithms is suitable for lowcost medium-precision drive applications. Experimental results, realized on Texas Instruments F28335 DSP, illustrating the performance of novel current limitation technique and sensorless control, are included.

\section{Introduction}

Five-phase induction machines (5pIMs) have some advantages and drawbacks over three-phase induction machines (3pIMs). One of the biggest advantages is lower current per phase for the same phase voltage and power rating. This results in less stress of semiconductor components, which is favorable for high-voltage machines [1]. Further advantages are lower torque pulsations, less harmonic content, and higher reliability. Because of the higher number of phases, the biggest drawbacks of 5pIM are higher switching losses and more complex control algorithms compared to conventional 3pIM. The application class for 5pIM contains electric and hybrid cars, aircraft and spaceship applications, marine propulsion systems, and high-power traction drives [2, 3]. 5pIMs are especially suitable for safety-critical applications requiring a high degree of redundancy. The degrees of freedom available in 5 pIM which do not exist in 3pIM have opened up many new research areas, such as different stator winding connection issues [4] or wound-rotor direct drives [5]. The possibility of redundancy in 5pIM has resulted in improvement of faulttolerant capabilities, such as open switch fault detection $[6,7]$, open-phase fault detection and post-fault operation $[8,9]$, or rotor-bar fault analysis [10].

For many applications where the simplicity of control and total drive cost is an aim, $V / f$ control is preferable [11]. It requires a smaller number of PI controllers than fieldoriented control; it employs very simple control structures that result in lower demands on microprocessor resources. It does not require precise values of machine parameters [12]. For safety-critical drives with 5pIM requiring some level of redundancy, $V / f$ control may be used in the case of failure. A switchover of control structure from vector control to simple open-loop $V / f$ control is beneficial when there is a faulty state of the drive or speed sensor. Several control algorithms exist for $V / f$ control, with differences in the type of converter used, the type of variables controlled, and the open-loop vs. closed-loop type of control algorithm. A $V / f$-based algorithm that generates a trapezoidal induction waveform in the air gap was proposed in [13] where openloop control is used to impose a fundamental and third- 
harmonic component to the stator phases to increase the power capability of the machine. Injection of the 5 th order harmonic in the sinusoidal references for the 5p-VSI to increase the fundamental output voltage of sinusoidal PWM has been investigated in [14]. It was shown that the linear modulation range was increased and analogy with threephase sinusoidal PWM with third-harmonic injection was evidenced. Sensorless $V / f$ control with MRAS speed estimator was proposed in [15]. By employing proportionalresonant controllers, disturbance-free operation for opencircuit faults was achieved. The $V / f$ algorithm of 5pIM [15] was compared with a sensorless field-oriented control algorithm, and it provided the results in [16]. It was found that both algorithms deal with an open-phase fault with similar performance. However, field-oriented control is better for dynamic and steady-state performance, but the precise determination of machine parameters highly affected its performance.

The research question barely discussed in the literature is the limitation of drive current in $V / f$ control. Limitation of maximum drive current is an important but often overlooked aspect of $V / f$ control design, and it is unavoidable for industrial implementation. In $V / f$ control, the stator current is not controlled directly and options for current limitation are restricted. Some form of current limiting technique must be implemented in each $V / f$-controlled drive system to protect the motor and frequency converter against overcurrents. For 3 pIM, this problem has been discussed in [17]. The authors proposed a programmable ramp function generator (RFG) and two proportional-integral (PI) controllers. The programmable RFG provides current limiting during transients, and PI controllers limit the stator current in the steady state. The proposed solution has shown a satisfactory performance, but the synthesis of the PI controller has not been included. Another solution was proposed in [18], where an alternative cascade control structure with PID current controller was used for closed-loop $V / f$ control. Industrial drives employ unique structures for stator current limitation in $V / f$ control with one PI controller and programmable RFG [19] or with two PI controllers [20]. A commonly used name for this class of algorithms is $I_{\max }$ controller.

The contribution of this paper is stated as a novel $I_{\max }$ controller introduced for the operation with 5pIM drives. The proposed controller is less complex than those presented for 3 pIM but equally effective. Simulation and experimental verification will show its effectiveness for the current limitation. Furthermore, the design and stability analysis of the proposed controller is provided in the paper together with the slip compensation algorithm, which results in a simple sensorless control structure useful for medium-precision 5 pIM drives.

\section{Theory of $V / f$ Control}

Algorithms of $V / f$ control are based on a steady-state model of the machine. A phasor method is usually used for the analysis of steady-state models. If the airgap flux is maintained at a constant value, the stator voltage per phase is expressed as [21]

$$
\mathbf{V}_{S}=j \omega_{e} \lambda_{m}+\left(R_{S}+j X_{l S}\right) \mathbf{I}_{S},
$$

where $\mathbf{V}_{S}$ is the vector of stator voltage, $\mathbf{I}_{S}$ is the vector of stator current, $R_{S}$ is the stator phase resistance, $X_{l S}$ is the stator leakage reactance, $\omega_{e}$ is the electrical speed, and $\lambda_{m}$ is the vector of air gap flux. If the electrical speed is large enough (i.e., not at low frequencies), the following holds:

$$
\left|\lambda_{m}\right| \omega_{e}=\left|\mathbf{E}_{m}\right| \gg\left|\left(R_{S}+j X_{l S}\right) \mathbf{I}_{S}\right|,
$$

where $\mathbf{E}_{m}$ is the air gap voltage. Then, the stator phase voltage can be approximated with the air gap voltage:

$$
\left|\mathbf{V}_{S}\right| \approx\left|\boldsymbol{\lambda}_{m}\right| \omega_{e}
$$

This means that in the region where equation (3) holds, if the phase voltage is adjusted as follows:

$$
\frac{\mathbf{V}_{S}}{\omega_{e}}=\left|\lambda_{m}\right|=\text { const, }
$$

we will obtain constant air gap flux. Note that equation (3) is generally applicable for induction machines of several kilowatts and above and for frequencies above $20 \%$ of the nominal frequency. Equation (4) says that if we increase the frequency proportionally with the amplitude of the phase voltage, the air gap flux will remain roughly constant. This is a well-known definition of $V / f$ control [22]. If the air gap flux is constant and the load torque is below the value of the rated machine torque, the following equation can be derived for 5 pIM:

$$
T_{e} \approx \frac{5}{4} p\left|\lambda_{m}\right|^{2} \frac{\omega_{\text {SLIP }}}{R_{R}},
$$

where $T_{e}$ is the machine torque, $p$ is the number of poles, $\omega_{\text {SLIP }}$ is the slip angular speed, and $R_{R}$ is the rotor resistance. From equation (5), the torque of the machine is proportional to the squared air gap flux (that will be maintained constant) and proportional to the slip angular speed. If the air gap flux is constant, the torque can be controlled by the control of slip angular speed $\omega_{\text {SLIP }}$. The simplest control system for a 5pIM drive is the open-loop configuration shown in Figure 1. The frequency setpoint $f_{\mathrm{REF}}$, calculated from the speed setpoint, enters the $V / f$ function that calculates the stator voltage $V_{\mathrm{REF}}$. The PWM modulator uses the calculated phase voltages to create PWM signals for a five-phase voltage source inverter (5p-VSI) [23]. The frequency converter, which supplies the motor, produces sinusoidal symmetrical voltages. The inverter increases its output voltage to the maximum output voltage, which depends on the voltage $V_{\mathrm{DC}}$ of the DC link. When the maximum output voltage is reached, the inverter only increases the output frequency.

The amplitude of voltage $V_{\mathrm{REF}}$ is calculated in the $V / f$ function from the frequency $f_{\text {REF }}$ using the following relationship:

$$
V_{\mathrm{REF}}=V_{0}+K f_{\mathrm{REF}}
$$

where $V_{0}$ is the voltage boost that must be designed to cover the voltage drop on the stator resistance at low frequencies. Commonly, a fixed value up to $25 \%$ of the rated voltage or a 


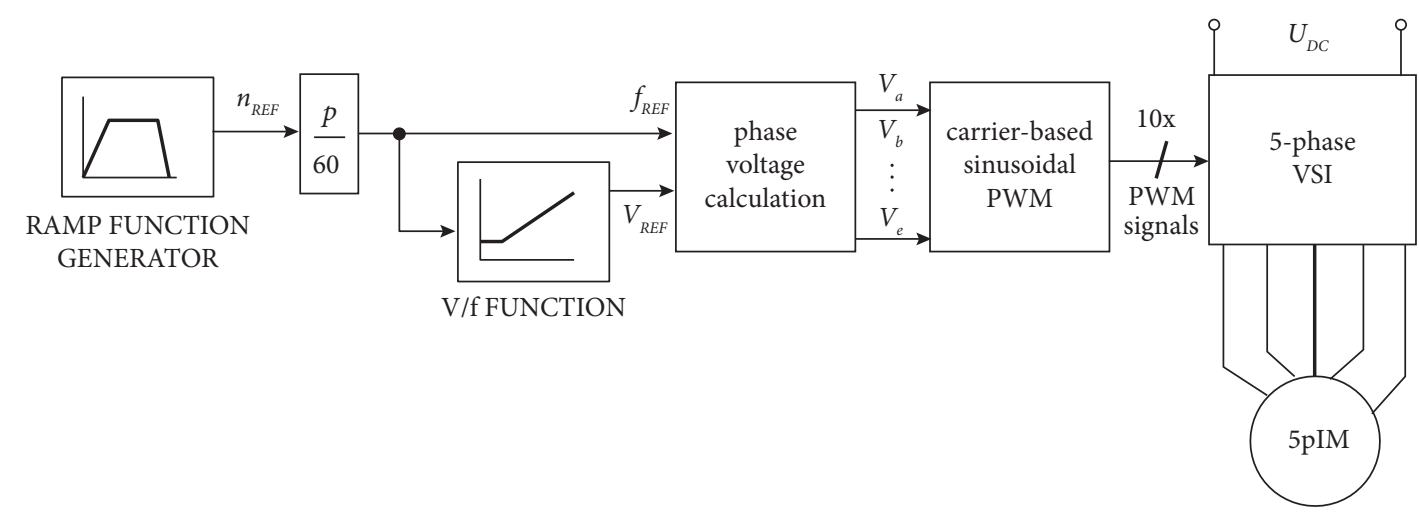

Figure 1: "Primitive" open-loop $V / f$ control for 5pIM without any sensors.

fixed value equivalent to the full load current is used to calculate $V_{0}$ [24]. A detailed procedure for calculation of $V_{0}$ and $K$ can be found in [25] considering admissible loading levels in a lower frequency range. The value of the voltage boost varies significantly with the change of stator resistance and total leakage inductance. The value of $V_{0}$ has a significant impact on total $V / f$ performance, and it needs to be calculated precisely. The configuration shown in Figure 1 is simple, and the speed and current sensors are not required, so it is very cost effective. But it has many drawbacks. Steadystate speed deviation is present, even under the no-load condition. The lack of feedback of the phase currents (or DC link current) means a risk of damaging $5 p$-VSI due to the possible presence of high currents. To overcome these drawbacks, the configuration in Figure 1 must be equipped with auxiliary circuits. A necessary operating condition is that the total drive current must be defined and limited.

\section{Novel Current Limitation Method}

Fast current protection must be established for the safe operation of the drive. The $V / f$ curve in Figure 1 might be implemented with different characteristics depending on the drive application class and demands for required energy savings [26]. However, for practical implementation of $V / f$ control, a circuit for limitation of drive total current must be always included in the control structure. It must be remembered that in $V / f$ control, a stator current cannot be controlled directly as in the case of vector control [27], where direct and quadrature current components are controlled and limited independently. This approach is not possible for $V / f$ control, and another method must be used. Here, we propose a solution for 5pIM shown as in Figure 2. It consists of three main components: total stator current calculation, voltage-reduction PI controller, and slip compensation.

3.1. Total Stator Current Calculation. The calculation of total drive current for $V / f$ control in industrial drives uses transformations of phase currents (compare [20] or [19]). Here lie the main differences between $V / f$ control of 3pIM and $5 \mathrm{pIM}$. The latter one uses the different transformation of phase current vectors into $\alpha \beta$ orthogonal system and, furthermore, employs a different way of transformation angle calculation needed for transformation from $\alpha \beta$ to $d q$ coordinate system.

The total current calculation in Figure 2 employs a measurement of currents in all machine phases. The phase currents are transformed to the stator coordinates using the following transformation matrix [28]:

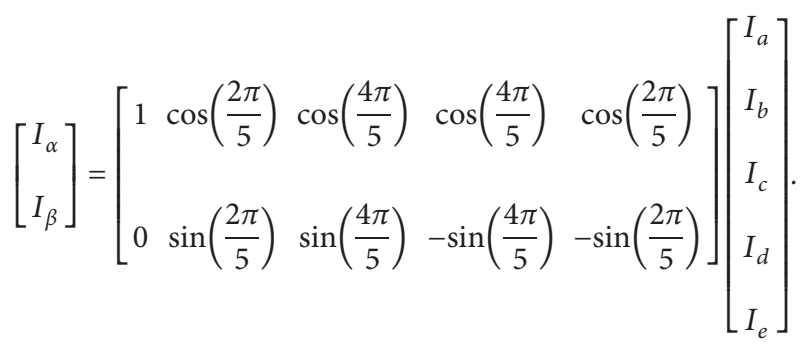

The Park transformation is used to transform currents to $d q$ coordinates. The phase transformation angle $\varphi_{\text {OUT }}$ needed for transformation from $\alpha \beta$ to $d q$ coordinate system is, unlike field-oriented control, obtained from the precalculated frequency $f_{\text {OUT }}$ as shown in Figure 2. Finally, the RMS value of total machine current $I_{\text {out }}$ is evaluated as

$$
I_{\mathrm{out}}=\sqrt{I_{s d}^{2}+I_{s q}^{2}}
$$

3.2. Design of Voltage-Reduction PI Controller. As the stator current is not directly controlled in $V / f$ control, the only ways to ensure current limitation are to reduce the reference voltage $V_{\mathrm{REF}}$, to reduce the reference frequency $f_{\mathrm{REF}}$, or to reduce both simultaneously. This can be achieved using several approaches [17-20]. In most cases, two PI controllers are used: one for reduction of voltage and the other for reduction of frequency. Other solutions need a special modification to the RFG that enables it to be frozen when the drive current exceeds its limit. However, no discussion about the stability of the current controller is provided in the available literature. Here, we propose a novel and less complex solution using only one PI controller and a feedback corrective term. Its design and stability will be researched as well. 


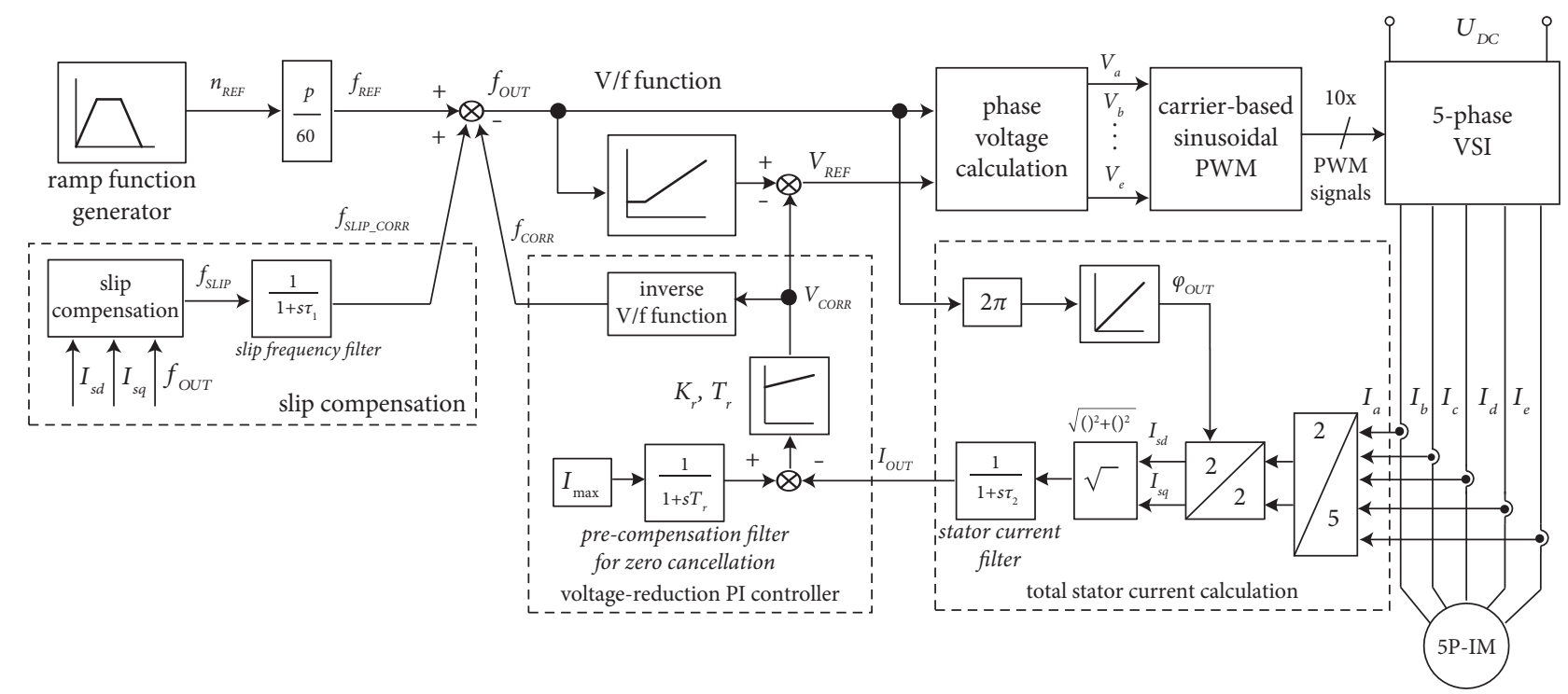

Figure 2: Advanced open-loop $V / f$ control with novel $I_{\max }$ controller and slip compensation.

In Figure 2, the measured feedback current given by equation (8) is compared to the maximum admissible current $I_{\max }$ and enters the voltage-reduction PI controller. It should be noted that the PI controller is employed here for reduction of the stator current by decreasing the stator voltage, i.e., PI controller is not used for the speed control. The output of the PI controller is voltage $V_{\text {corr }}$ that decreases the voltage magnitude that comes out from the $V / f$ function. An inverse $V / f$ function is calculated with the aim of the original function equation (6) as

$$
f_{\mathrm{CORR}}=\frac{1}{K}\left(V_{\mathrm{CORR}}-V_{0}\right) \text {. }
$$

If the motor current reaches the current limit during acceleration, the proposed controller reduces the output voltage to keep the current $I_{\text {OUT }}$ below the current limit $I_{\mathrm{MAX}}$. If the load on the motor is so high during stationary operation that the motor current reaches the current limit, the controller reduces the voltage and speed setpoint until a stable working point is set and the motor current drops into the permissible range. If the load is reduced, the controller increases the speed setpoint until the setpoint is reached and a new stable working point is reached.

A circuit for the synthesis of voltage reduction for the PI controller is shown in Figure 3. $F_{\mathrm{PI}}(s)$ is the transfer function of the voltage-reduction PI controller:

$$
F_{\mathrm{PI}}(s)=K_{r} \frac{1+s T_{r}}{s T_{r}},
$$

where $T_{c}$ is given as the sum of computational delay and delay of the sample-hold mechanism [29]. It is calculated from the PWM carrier frequency $f_{s}$ as follows:

$$
T_{c}=\frac{3}{2 f_{s}}
$$

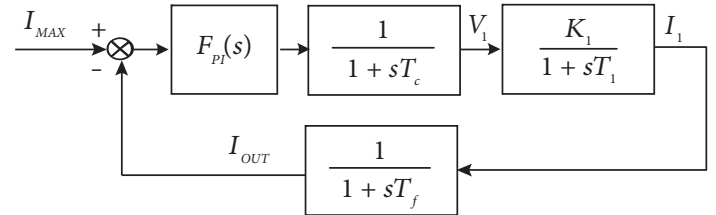

FIGURE 3: A block scheme for synthesis of voltage-reduction PI controller.

where $K_{1}=1 / R_{s}$ is the stator gain, $T_{1}$ is the electrical time constant of the stator, and $T_{f}$ is the time constant of the current sensing path which is given as

$$
T_{f}=T_{\text {cur_samp }}+\tau_{2},
$$

where $T_{\text {cur_samp }}$ is the stator current sampling period and $\tau_{2}$ is the time constant of total stator current as shown in Figure 2.

Usually, $\left(T_{f}+T_{c}\right) \ll T_{1}$ holds, and a substitute time constant $T_{\Sigma}=T_{f}+T_{c}$ can be used. Then, the parameters of the PI controller can be calculated using the pole-placement method.

3.3. Synthesis of Voltage-Reduction PI Controller. The closedloop transfer function of the system in Figure 3 including the PI controller is given as

$$
G(s)=\frac{b_{1} s+b_{0}}{s^{3}+a_{2} s^{2}+a_{1} s+a_{0}} .
$$

Parameters of the system given by equation (13) can be found in Table 1 . The system has 3 poles and one zero. It can be shown that zero in nominator might be cancelled by precompensation with a low-pass filter with the time constant $T_{r}$ (precompensation filter in Figure 2). By comparing the compensated system equation (13) with the desired closed-loop transfer function, 
TABle 1: Parameters of closed-loop transfer functions and parameters for PI controller synthesis.

\begin{tabular}{lcc}
\hline Real CLTF parameters & Reference CLTF parameters & Parameters for PI controller synthesis \\
\hline$b_{1}=\left(K_{1} K_{r} / T_{1} T_{\Sigma}\right)$ & - & $T_{1}=122 \mathrm{~ms}$ \\
$b_{0}=\left(K_{1} K_{r} / T_{1} T_{r} T_{\Sigma}\right)$ & $b_{W 0}=\alpha d \omega_{0}^{3}$ & $T_{c}=0.375 \mathrm{~ms}$ \\
$a_{2}=\left(\left(T_{1}+T_{\Sigma}\right) / T_{1} T_{\Sigma}\right)$ & $a_{W 2}=\alpha d \omega_{0}+2 d \omega_{0}$ & $T_{f}=2.3 \mathrm{~ms}$ \\
$a_{1}=\left(\left(1+K_{1} K_{r}\right) / T_{1} T_{\Sigma}\right)$ & $a_{W 1}=2 \alpha d^{2} \omega_{0}^{2}+\omega_{0}^{2}$ & $d=0.4 t_{r}=23 \mathrm{~ms}$ \\
$a_{0}=\left(K_{1} K_{r} / T_{1} T_{r} T_{\Sigma}\right)$ & $a_{W 0}=\alpha d \omega_{0}^{3}$ & $\tau_{1}=500 \mathrm{~ms} \tau_{2}=2 \mathrm{~ms}$ \\
\hline
\end{tabular}

$$
G_{W}(s)=\frac{b_{W 0}}{s^{3}+a_{W 2} s^{2}+a_{W 1} s+a_{W 0}},
$$

where $d$ is damping, $\omega_{0}$ is the natural frequency, and $\alpha$ is the arbitrary displacement of the 3 rd pole's real axis. Using the following poles:

$$
\begin{aligned}
& s_{1}=-d \omega_{0}+j \omega_{0} \sqrt{1-d^{2}}, \\
& s_{2}=-d \omega_{0}-j \omega_{0} \sqrt{1-d^{2}}, \\
& s_{3}=\alpha\left(-d \omega_{0}\right),
\end{aligned}
$$

PI controller values can be found as

$$
\begin{aligned}
\alpha & =\frac{T_{1}+T_{\Sigma}}{d \omega_{0} T_{1} T_{\Sigma}}-2, \\
K_{r} & =\frac{1}{K_{1}}\left[T_{\Sigma} T_{1} \omega_{0}\left(2 \alpha d^{2}+1\right)^{2}-1\right], \\
T_{r} & =\frac{K_{r} K_{1}}{\alpha d \omega_{0}^{3} T_{1} T_{\Sigma}} .
\end{aligned}
$$

The final parameters in equation (16) enable the design of a PI controller based on the desired damping and desired natural frequency. However, the real axis displacement $\alpha$ of pole $s_{3}$ depends on the desired values. An improper combination of desired values may cause a shift of pole $s_{3}$ to unstable area. A stability analysis is therefore necessary. By using Routh stability criterion, we can show that the PI controller parameters have to meet the following conditions:

$$
\begin{aligned}
& T_{r}>\frac{K_{1} T_{1} T_{\Sigma}}{T_{1}+T_{\Sigma}} \frac{K_{r}}{1+K_{1} K_{r}} \\
& K_{r}>\frac{T_{r}\left(T_{1}+T_{\Sigma}\right)}{K_{1}\left(T_{1} T_{\Sigma}-T_{r}\left(T_{1}+T_{\Sigma}\right)\right)} .
\end{aligned}
$$

The performance of the controller is highly dependent on the value of $\tau_{2}$ and the placement of $\alpha$. Decrease of damping coefficient $d$ value results in more accurate current limitation. On the other hand, it increases oscillations of $I_{\text {OUT }}$. For fixed value of $d$, the natural frequency $\omega_{0}$ or settling time must be chosen to ensure $s_{3}$ is located within $\alpha=\{0.8-1.15\}$.

\section{Slip Compensation}

The torque and the slip of the machine increase during loading. This is observed from equation (5). Without slip compensation in the control structure, a steady-state speed deviation will occur. For $V / f$ control, this deviation is usually treated using two different approaches: a closed-loop structure with speed measurement, as shown in Figure 4(a), and an open-loop structure, for example, the one given in Figure 4(b). All of these methods are part of the large group of slip compensation methods summarized in [30].

The reference speed and the actual speed in Figure 4(a) are compared, and the resulting slip speed enters the PI controller. The output of the PI controller is saturated by the maximum and minimum values of the slip frequency $f_{\text {slip }}$, which is then added to the actual frequency, resulting in output frequency $f_{\text {out }}$ for $V / f$ control (compare with Figure 2). This method can achieve reasonable accuracy, but it has two disadvantages. It is costly due to the necessary speed measurement. This measurement can be replaced by some speed estimation algorithm. Nevertheless, it will still require PI controller tuning and additional loops for speed estimation, which makes it more complex. This approach would not be preferable for simple and low-cost $V / f$ control. The proposed solution, shown in Figure 4(b), is based on the following principle.

If the drive output voltage and frequency are held constant when the motor load is increased, the shaft speed will decrease due to additional required torque, which results in a greater amount of slip. This will result in an increase in current that can be detected by the current transducers. Slip compensation automatically compensates for a decrease in the speed by applying additional output frequency to the existing output frequency. The final output frequency is "shifted" to a higher value, resulting in an increase in actual speed. Note that the amount of slip does not decrease, and the motor shaft still slips back. However, the speed deviation is partially reduced. The following relationship between measured currents and slip frequency was found [30]:

$$
f_{\text {SLIP }}=\frac{R_{R}}{2 \pi L_{R}} \frac{I_{s q}}{I_{s d}} .
$$

The calculated slip frequency $f_{\text {SLIP }}$ in Figure $4(\mathrm{~b})$ is saturated by the minimum and maximum values of the slip and then multiplied by the calculated nominal slip value $s_{n}$ in $\mathrm{Hz}$ to obtain the relative slip. The relative slip is then multiplied by adjusting the function that turns off the slip compensation for 0 to $6 \%$ of the nominal frequency, and the slip compensation is increased linearly up to $10 \%$ of nominal frequency. For higher frequencies, the full-slip compensation is applied. Adjusting the function reduces the slip compensation for lower frequencies as instabilities may occur in that region [31]. The final corrective term $f_{\text {SLIP_CORR }}$ is then added to the output frequency as seen in 


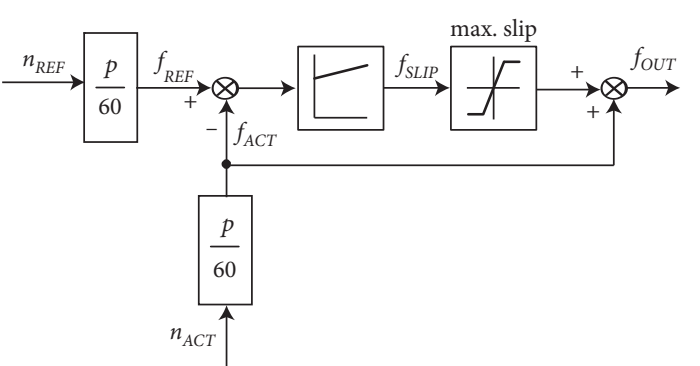

(a)

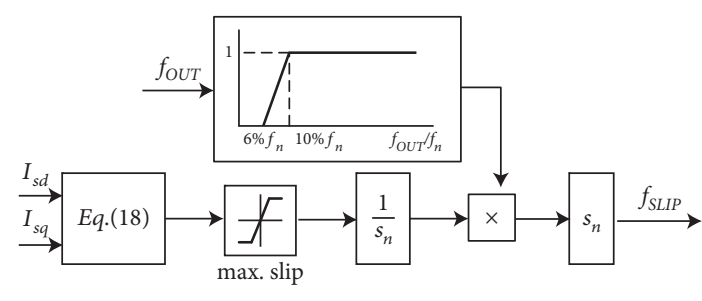

(b)

Figure 4: (a) Closed-loop slip compensation with speed measurement (commonly used method). (b) Open-loop slip compensation based on current measurement (proposed solution).
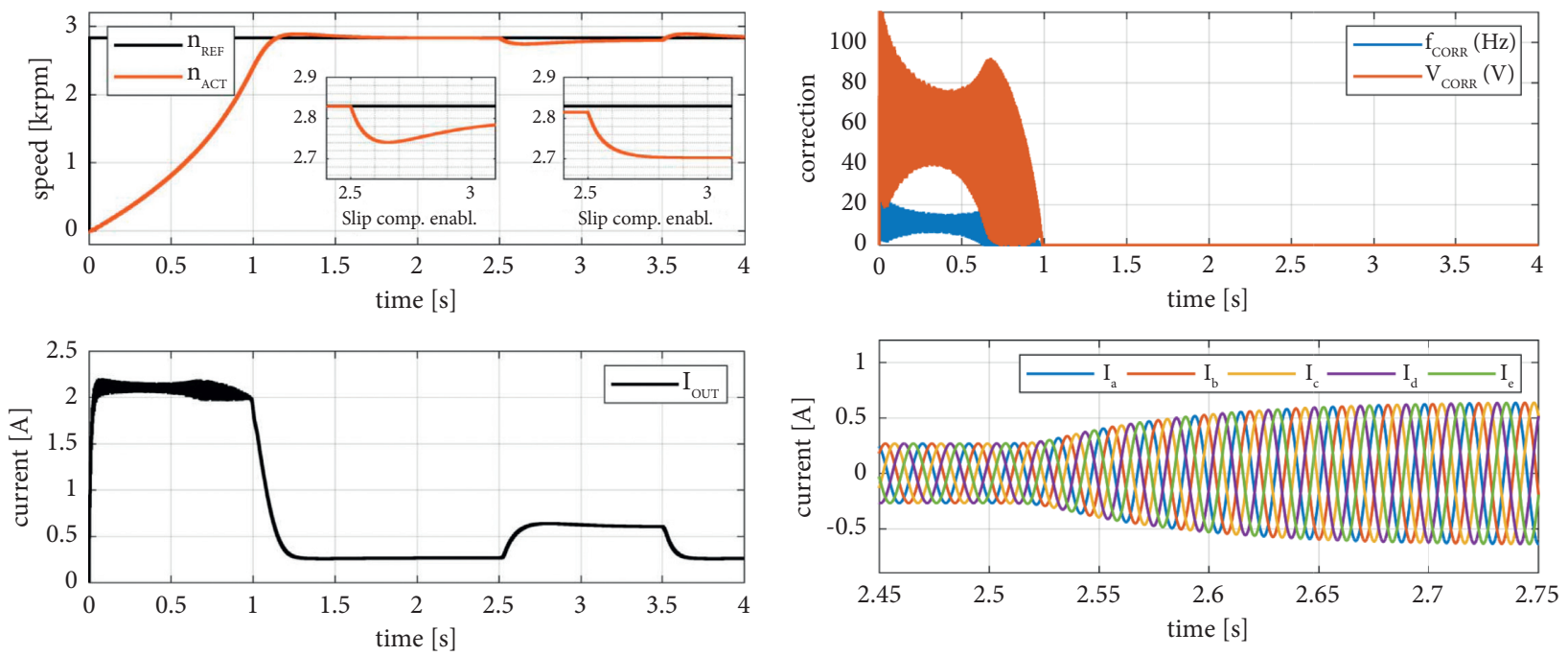

(a)

(b)
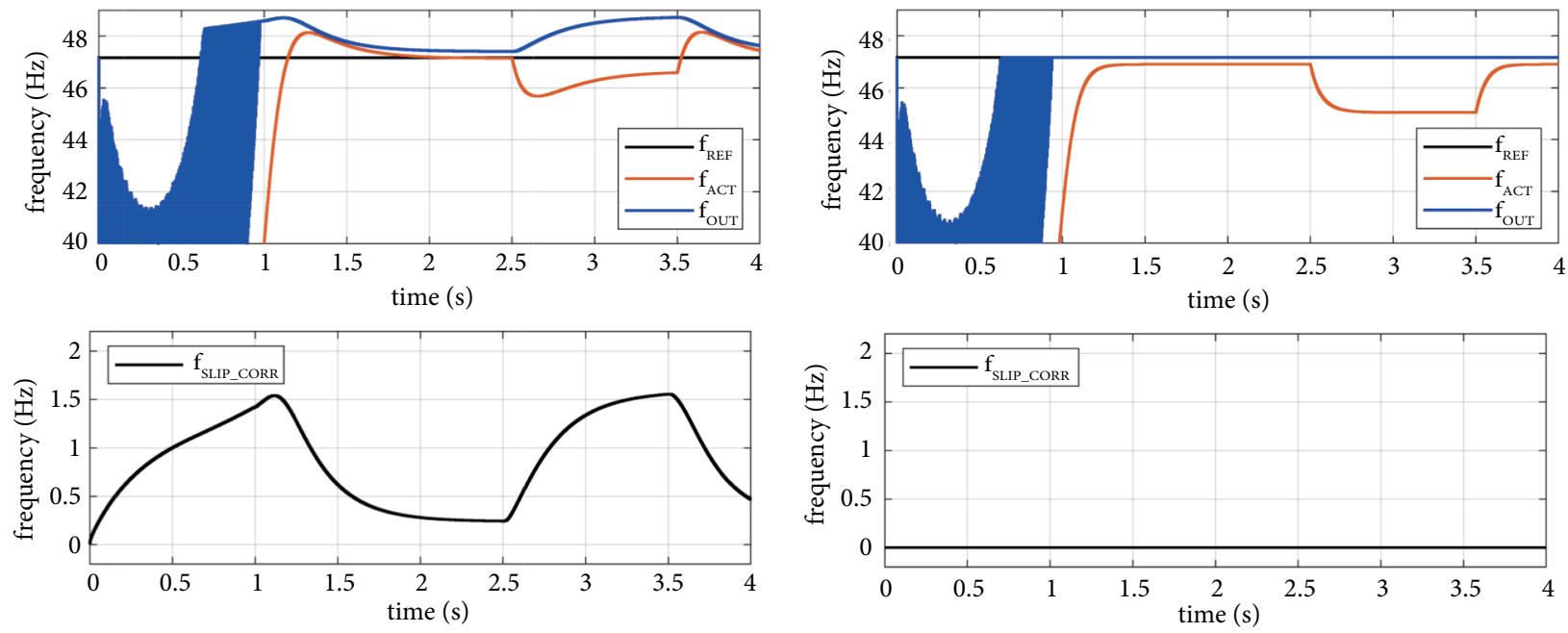

(c)

(d)

FiguRE 5: Simulation results for $n_{N}$ : (a) reference and actual speed and total drive current; (b) responses of corrective terms for current limitation and details of phase currents; (c) frequency responses for enabled slip compensation; (d) frequency responses for disabled slip compensation. 

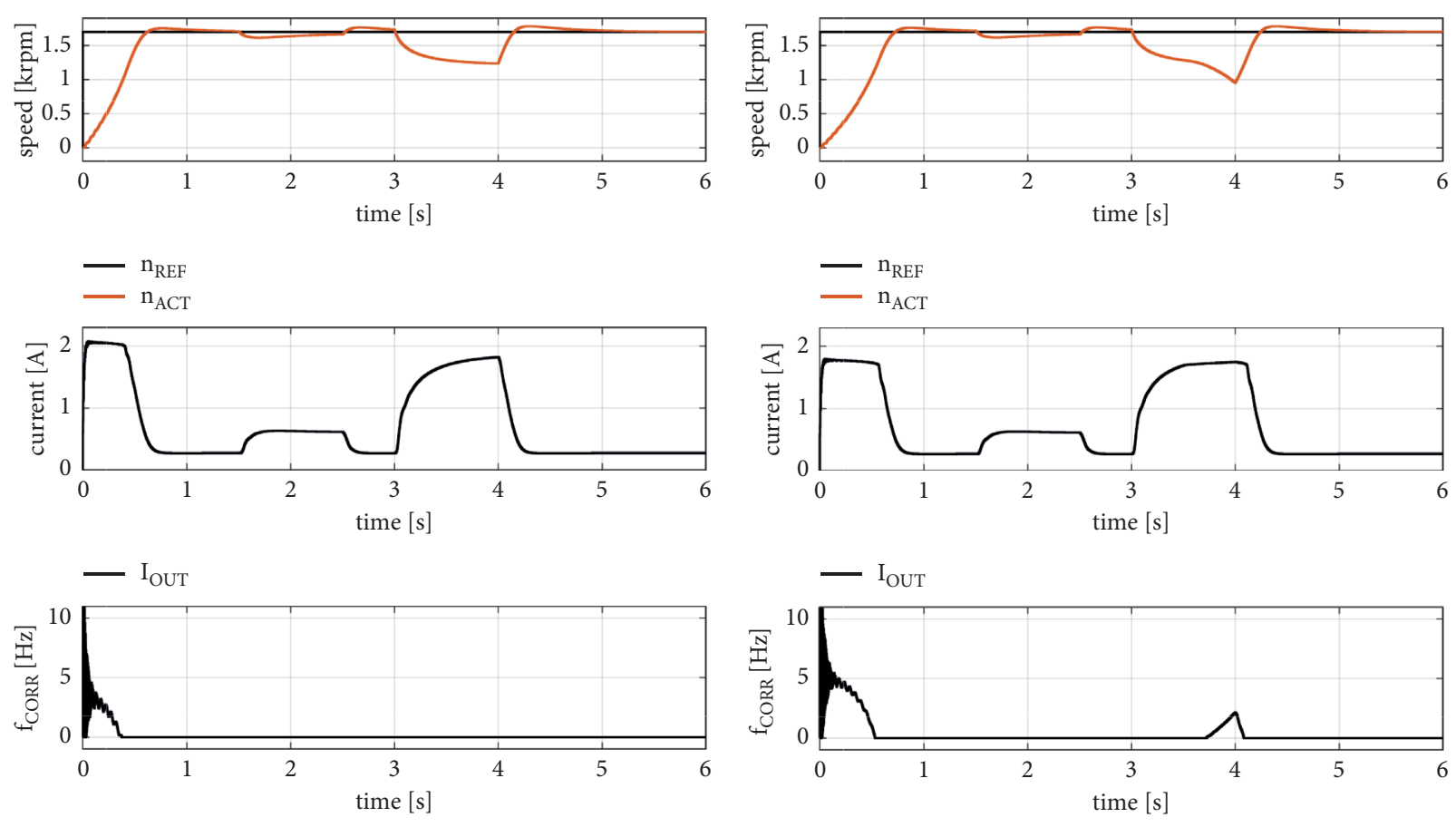

$-\mathrm{f}_{\mathrm{CORR}}$

$-\mathrm{f}_{\mathrm{CORR}}$

(a)

(b)
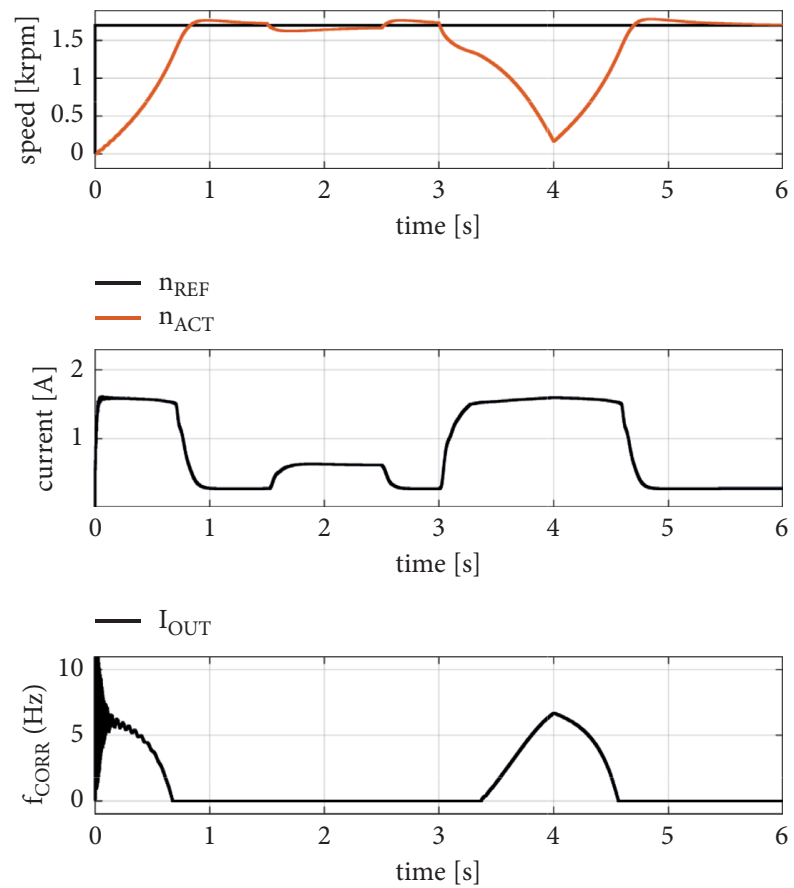

$-\mathrm{f}_{\mathrm{CORR}}$

(c)

Figure 6: Simulation results for $60 \%$ of $n_{N}$ and different values of current limitation. (a) $I_{\mathrm{MAX}}=120 \% I_{N}$. (b) $I_{\mathrm{MAX}}=I_{N}$. (c) $I_{\mathrm{MAX}}=90 \% I_{N}$.

Figure 2. This method does not require information about the actual speed nor any tuning procedure, and it is very simple. However, a knowledge of the rotor resistance $R_{R}$ and inductance $L_{R}$ is required, but these parameters are often automatically calculated during the initial commissioning of the drive. 


\section{Simulation Results}

5.1. Current Limitation and Slip Compensation. Simulation results for the proposed algorithm are shown in Figures 5 and 6 . The simulation was provided for the starconnected model of 5pIM, and machine parameters are given in Table 2. Values $K=4,39 \mathrm{~V} / \mathrm{Hz}$ and $V_{0}=10,6 \mathrm{~V}$ were used for $V / f$ control, based on guidelines given in [25].

Figure 5 shows a step reference change from zero to the nominal speed $2830 \mathrm{rpm}$ and loading by $50 \%$ of nominal load torque at $t=2,5 \mathrm{~s}$. The machine was unloaded at $t=3,5 \mathrm{~s}$. The maximum drive current was set to $2 \mathrm{~A}$ (approx. $120 \%$ of the nominal motor current). The performance of the current limitation is shown in (B) in Figure 5(a), where it can be observed that the current limitation works correctly during the acceleration phase. The performance of the slip compensation is shown in (A) in Figure 5(a), where detailed speed drops for enabled and disabled slip compensation are shown for comparison. The performance of the slip compensator is also shown in Figure 5(c), where the upper figure shows responses of drive frequencies when the slip compensation was enabled. Enabled slip compensation produces a corrective frequency signal $f_{\text {SLIP CORR }}$ that corresponds to the estimated value of actual slip. This signal is added to the reference frequency $f_{\text {REF }}$ what causes the shift of $f_{\text {OUT }}$ frequency. The frequency value $f_{\text {OUT }}$ is given as (compare with Figure 2)

$$
f_{\mathrm{OUT}}=f_{\mathrm{REF}}+f_{\mathrm{SLIP} \_\mathrm{CORR}}-f_{\mathrm{CORR}} .
$$

The amount of slip does not actually decrease, but it is simply shifted. For disabled compensation in Figure 5(d), the slip correction $f_{\text {SLIP_CORR }}$ has zero value, and consequently, there is a constant steady-state speed error even for unloaded drive.

Different current limits are shown in Figure 6. It shows a step reference change from zero to the $50 \%$ of nominal speed. Then, two values of load torque were applied: $50 \%$ at $t=1,5 \mathrm{~s}$ and $120 \%$ of nominal torque at $t=3 \mathrm{~s}$. Three different current limits were tested. It can be observed that the current limitation works correctly during the acceleration phase and for higher load torque values. In both cases, the total drive current does not exceed its preset maximum value. For the lower value of load torque, the current limitation does not actuate as it is not necessary. Details of corrective term $f_{\text {CORR }}$ being active in the current limitation are included in Figure 6 at the bottom. It can be observed that for the higher load torque value, the value of $f_{\text {CORR }}$ rises up and the actual speed of the drive falls down up to the instant when the drive suddenly becomes unloaded at $t=4 \mathrm{~s}$. After that, the actual drive speed quickly recovers to its setpoint. It can be concluded that the drive current limitation works correctly under different conditions.

5.2. Analysis of Mismatch in Rotor Resistance. The control structure in Figure 2 depends on the measurement of currents which are affected by the change of parameters. The slip compensation heavily depends on the value of rotor resistance $R_{R}$. It is found that $R_{R}$ is difficult to be
TABle 2: Parameters of five-phase induction machine.

\begin{tabular}{lccc}
\hline Parameter & Symbol & Value & Dimension \\
\hline Rated power & $P$ & 1,5 & $\mathrm{~kW}$ \\
Rated speed & $n$ & 2830 & $\mathrm{rpm}$ \\
Rated current & $I$ & 1,7 & $\mathrm{~A}$ \\
Rated slip & $\mathrm{slip}$ & 2,8 & $\mathrm{~Hz}$ \\
Rated voltage & $V(\mathrm{star})$ & 230 & $\mathrm{~V}$ \\
Stator resistance & $R_{S}$ & 9,5 & $\Omega$ \\
Rotor resistance & $R_{R}$ & 6,68 & $\Omega$ \\
Total inertia (test + load machine) & $J$ & 0,01148 & $\mathrm{kgm}^{2}$ \\
Main inductance & $L_{h}$ & 1,114 & $\mathrm{H}$ \\
Stator leakage inductance & $L_{1 \sigma}$ & 0,0269 & $\mathrm{H}$ \\
\hline
\end{tabular}

accurately measured since is not easily accessible. Furthermore, rotor resistance varies significantly with the motor temperature. The normal temperature change of $80^{\circ} \mathrm{C}$, which is expected in induction machines with insulation class $\mathrm{B}$, causes a change in rotor and stator resistances of 34\% [32]. This must be investigated because the rotor resistance has a strong link with the speed. Therefore, a mismatch in rotor resistance was tested in this section. The nominal value or resistance has been used for the calculation of slip compensation, and then actual rotor resistance was varied for three different values: $R_{R}, 140 \%$ of $R_{R}$, and $180 \%$ of $R_{R}$. The results are shown in Figure 7 . Two different step changes of reference speed were executed, followed by the step load torque of $60 \%$ of nominal torque in $t=2,5 \mathrm{~s}$. It can be observed that with the increase of rotor resistance value, the total drive current is decreasing. The mismatch in the rotor resistance value has the highest impact to the load torque rejection capability of the drive. However, it must be emphasised that the machine is operated only as a sensorless drive. Thus, it is very difficult to compensate actual speed drop without any speed sensor, relying only on current measurements that are strongly affected by mismatched parameters.

\section{Experimental Results}

Experimental tests were performed for the real prototype of 5 pIM with the parameters given in Table 2. The control algorithm to generate real-time executable code was prepared in MATLAB/Simulink and then compiled and loaded to the Texas Instruments TMS320F28335 DSP. The modular model approach [33] for rapid control prototyping with two-level architecture was used, and we can find the implementation details in [23]. The experimental setup comprises the 5pIM with distributed winding, a loading induction machine controlled by an industrial converter, and a prototype of fivephase VSI with IGBT transistors. An interrupt service routine for the $V / f$ algorithm was triggered with $T_{s}=250 \mu \mathrm{s}$, and the PWM frequency was fixed to $4 \mathrm{kHz}$. We set the DC link value to $V_{\mathrm{DC}}=400 \mathrm{~V}$ because of the hardware setup limitations. The experimental setup is shown in Figure 8.

Experimental results for verification of drive current limitation during acceleration are given in Figure 9. At first, the drive is magnetized at time $t=0,1 \mathrm{~s}$. The value of total current $I_{\text {out }}$ in this period is given by the applied voltage 

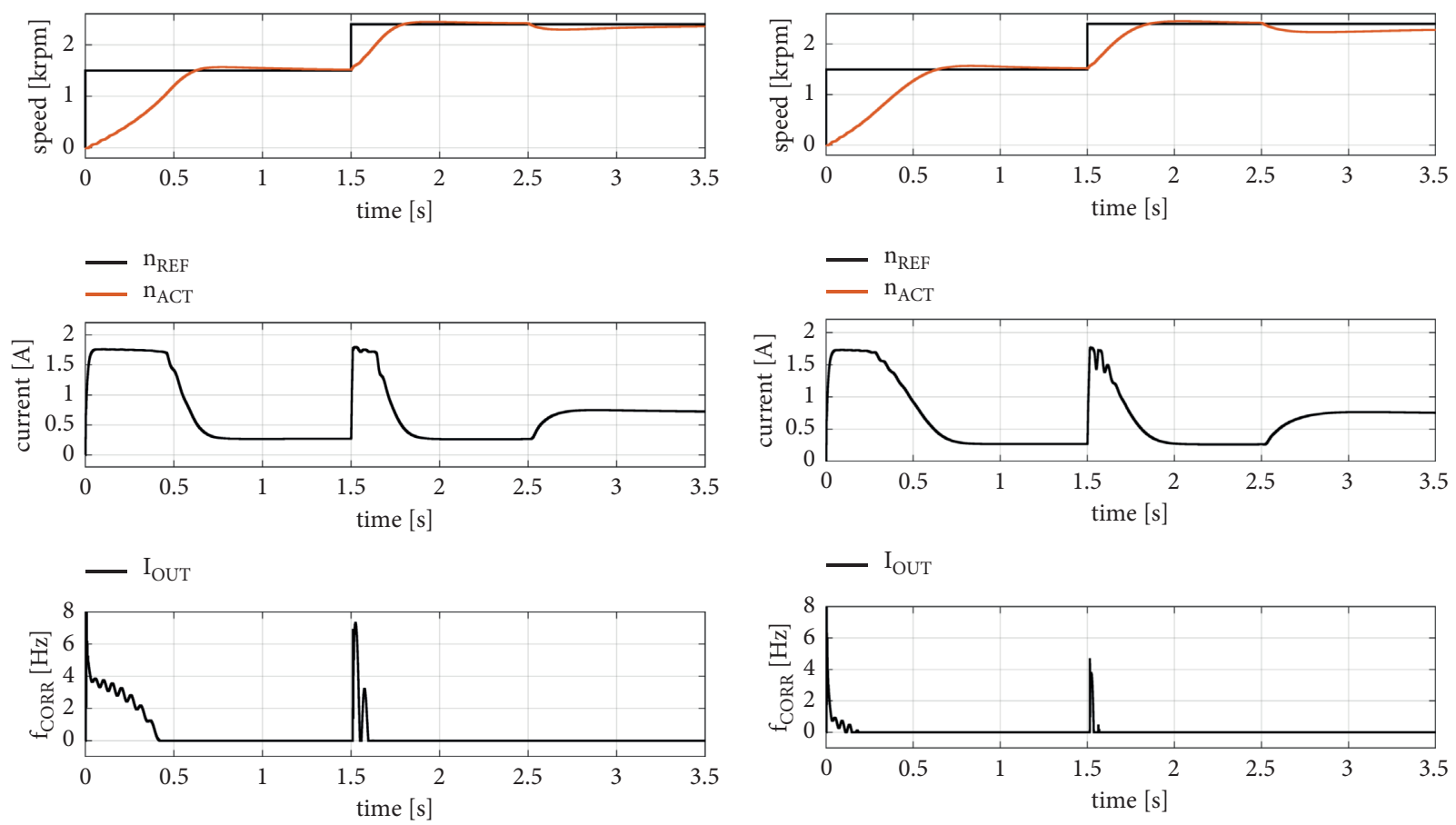

- $\mathrm{f}_{\mathrm{CORR}}$

$-\mathrm{f}_{\mathrm{CORR}}$

(a)

(b)
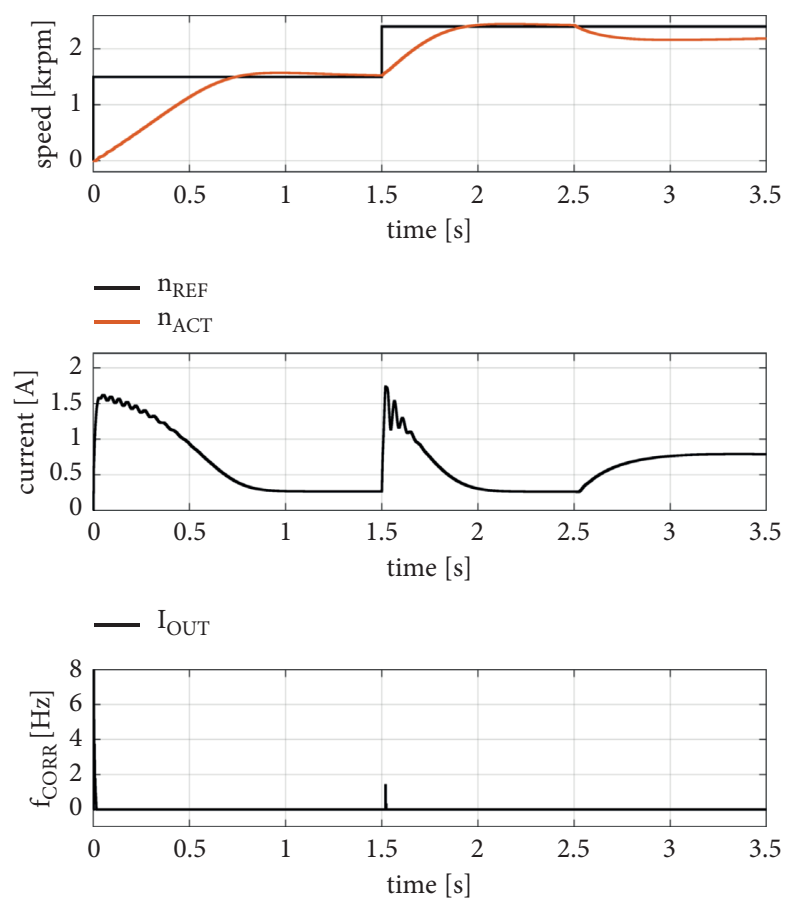

$-\mathrm{f}_{\mathrm{CORR}}$

(c)

FiguRE 7: Simulation results for step reference of speed and different values of rotor resistance. (a) Nominal rotor resistance $R_{R}$. (b) Rotor resistance changed to $140 \%$ of $R_{R}$. (c) Rotor resistance changed to $180 \%$ of $R_{R}$. 


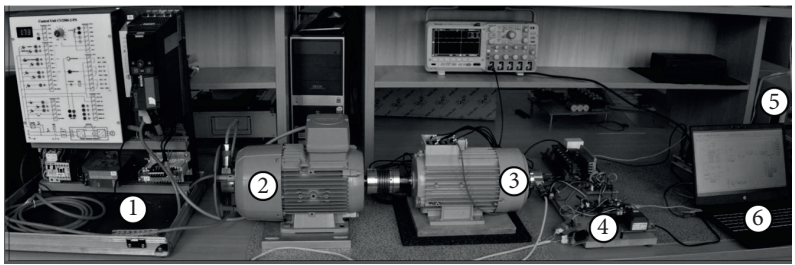

FiguRE 8: Experimental setup: (1) Siemens frequency converter for loading drive, (2) $3 \mathrm{~kW}$ loading machine, (3) prototype of $1.5 \mathrm{~kW}$ fivephase induction machine, (4) prototype of VSI with five-phases and control DSP with Texas Instruments 28335 processor, (5) voltage source for DC link, and (6) programming PC for automated code generation from MATLAB/Simulink.
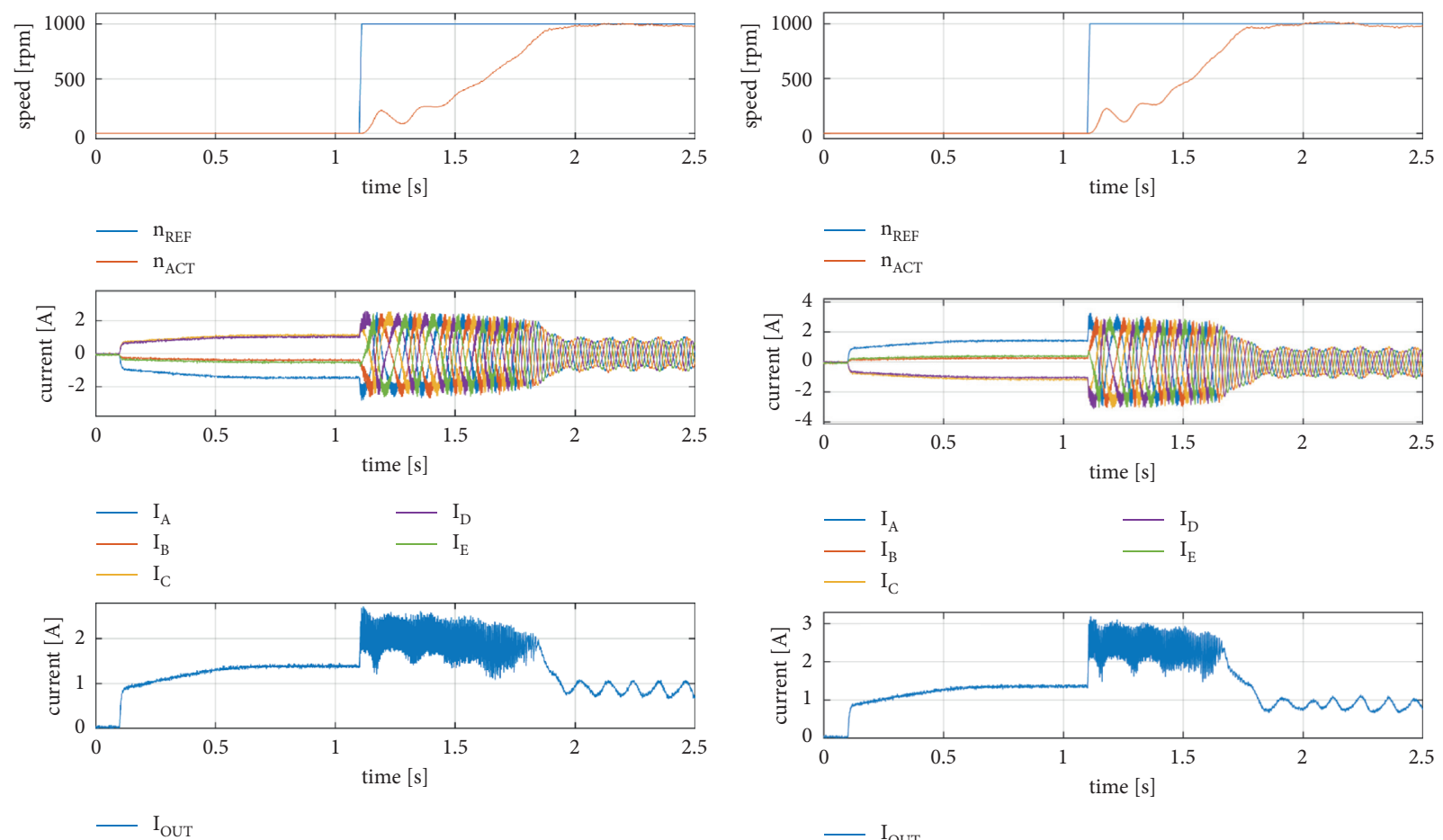

(a)

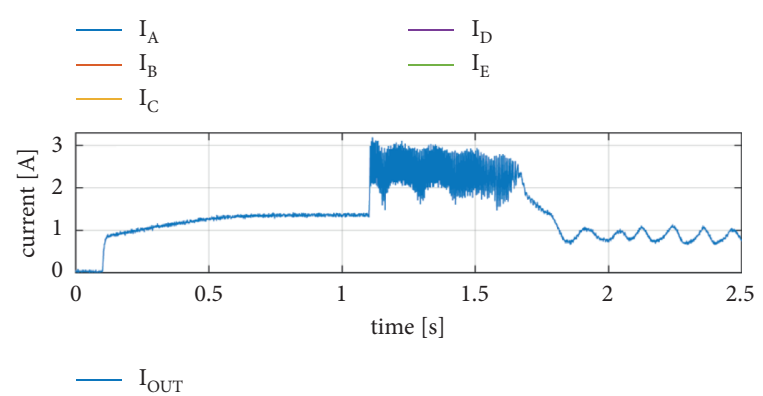

(b)

Figure 9: Experimental results: acceleration with different current limitations. (a) $I_{\max }=2 \mathrm{~A}$. (b) $I_{\max }=2,5 \mathrm{~A}$.

boost value $V_{0}=10,5 \mathrm{~V}$. The value of the voltage boost is the same for different $I_{\mathrm{MAX}}$ settings. At $t=1,21 \mathrm{~s}$, the fast ramp $0,01 \mathrm{~s}$ was applied to the reference speed to change from zero to $1000 \mathrm{rpm}$. It can be observed that the output current $I_{\text {out }}$ and the phase currents $I_{a}$ to $I_{e}$ are limited to given maximum values during acceleration. The lower the value of the maximum current is, the longer the acceleration transients take.

Experimental results for drive current limitation under steady-state loading tests are shown in Figure 10. For both cases, the maximum current limit was set to $2 \mathrm{~A}$. Slip compensation was disabled in Figure 10(a). Therefore, a steady-state speed error is present even for unloaded drive. The slip compensation was re-enabled in Figure 10(b). In both experiments, the drive was first loaded with a step load torque value of $2 \mathrm{Nm}$ (approx. $t=9.5 \mathrm{~s}$ ), then unloaded, and then again loaded with a step load torque value of $2.5 \mathrm{Nm}$ (approx. $t=13.1 \mathrm{~s}$ ). For higher load torque value, maximum current level of $2 \mathrm{~A}$ of the drive was exceeded and the actual speed started to decrease. We can observe that the control algorithm keeps the total drive current at its maximum value. If this situation lasts longer, the drive will have to be switched off. In this experiment, the drive was unloaded after two seconds so that the actual speed recovered to its previous reference value. When comparing Figures 10(a) and 10(b), the effect of the slip compensation is visible in detailed speed responses. For disabled slip compensation, the speed dropped from 1000 to $900 \mathrm{rpm}$ in Figure 10(a), whereas in Figure 10(b), it dropped only to $950 \mathrm{rpm}$ and then started to recover slowly to its setpoint. 

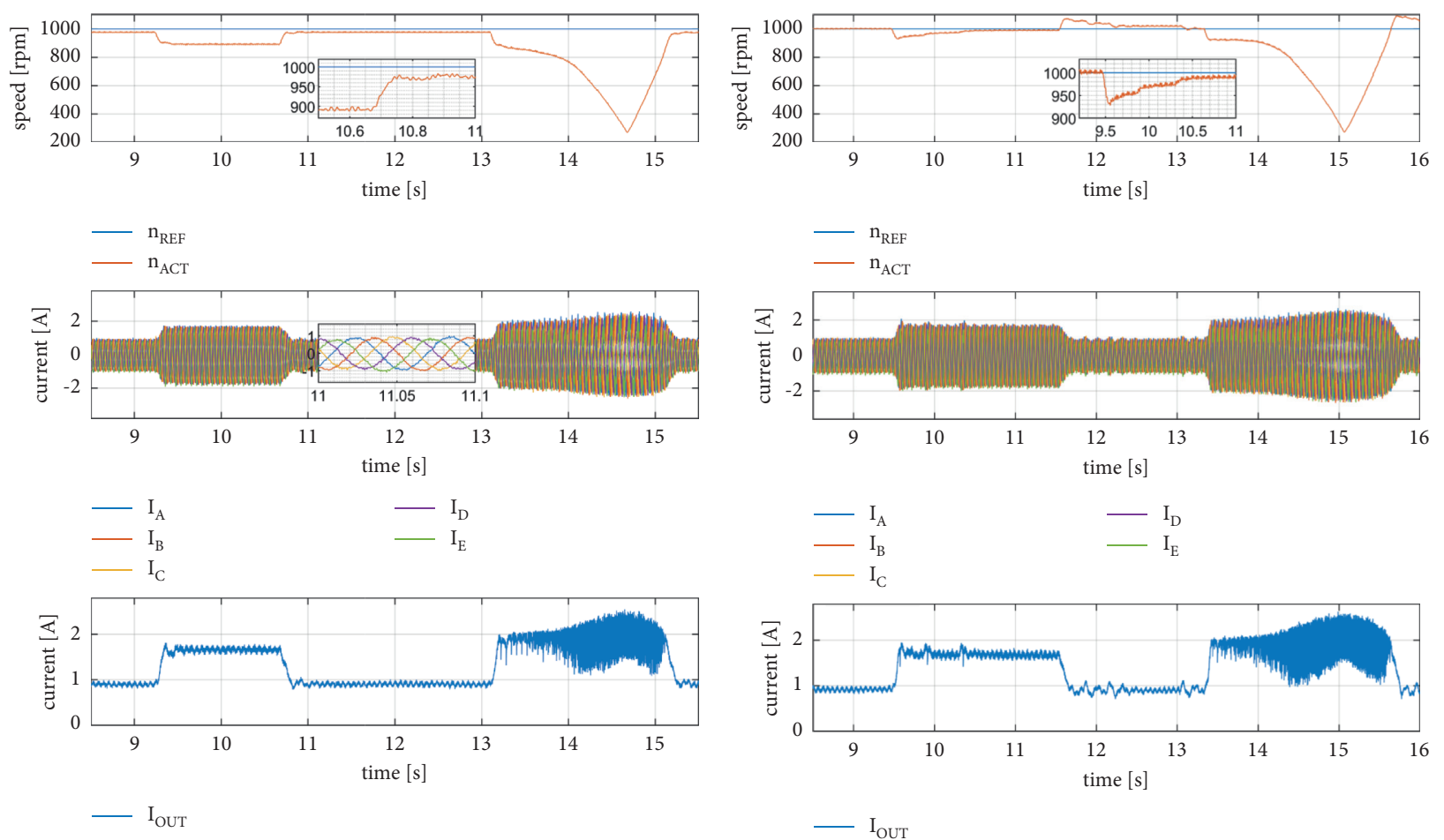

(a)

(b)

Figure 10: Experimental results for steady-state loading with and without slip compensation: (a) slip compensation disabled; (b) slip compensation enabled.

\section{Conclusion}

In this paper, a current limiting technique for sensorless $V / f$ algorithm for five-phase induction machines is presented. Two elements of the control structure have been studied particularly. At first, a novel drive current limitation algorithm was introduced and provided, employing only one PI controller. Existing industrial solutions use at least two PI controllers or one PI controller in combination with a freezing function in the ramp function generator. We overcame this problem by using feedback inverse signal to reduce the reference frequency if an overcurrent condition is detected. Thus, presented solution does not require any modification of the ramp function generator compared to other solutions, and it is less complex. Next, we presented a slip compensation technique for the improvement of steady-state speed control. It was shown that the slip compensation technique developed for three-phase induction machines can successfully be applied also to five-phase induction machines with the differences in the used transformation matrix that have been also discussed in the paper. The proposed combination of control algorithms enables sensorless operation with no speed measurement or phase voltage measurement. It is purely based on phase current measurement, but it requires a knowledge of rotor parameters. We usually obtain these values during the industrial drive's commissioning procedure. The future work should be focused on the operation of the controller in the regenerative mode and field weakening region.

\section{Data Availability}

The datasets used in this article are available from the corresponding author on reasonable request.

\section{Conflicts of Interest}

The authors declare that they have no conflicts of interest.

\section{Acknowledgments}

This study was supported by the Slovak Research and Development Agency under contract nos. APVV-18-0436, APVV-16-0270, and APVV-19-0210 and the Scientific Grant Agency of the Ministry of Education of the Slovak Republic under the project VEGA 1/0493/19.

\section{References}

[1] E. Levi, R. Bojoi, F. Profumo, H. A. Toliyat, and S. Williamson, "Multiphase induction motor drives-a technology status review," IET Electric Power Applications, vol. 1, no. 4, p. 489, 2007.

[2] H. A. Toliyat, "Analysis and simulation of five-phase variablespeed induction motor drives under asymmetrical connections," IEEE Transactions on Power Electronics, vol. 13, no. 4, pp. 748-756, 1998.

[3] A. K. Panda and R. Pandey, "Performance evaluation of controlled QZSI fed five-phase induction motor under voltage sag and interruption," International Transactions on Electrical Energy Systems, vol. 30, no. 1, Article ID e12166, 2020. 
[4] A. S. Abdel-Khalik, S. Ahmed, and A. M. Massoud, "Dynamic modeling of a five-phase induction machine with a combined star/pentagon stator winding connection," IEEE Transactions on Energy Conversion, vol. 31, no. 4, pp. 1645-1656, 2016.

[5] G. Rizzoli, M. Mengoni, A. Tani, G. Serra, L. Zarri, and D. Casadei, "Wireless power transfer using a five-phase wound-rotor induction machine for speed-controlled rotary platforms," IEEE Transactions on Industrial Electronics, vol. 67 , no. 8, pp. 6237-6247, 2020.

[6] I. González-Prieto, M. J. Duran, N. Rios-Garcia, F. Barrero, and C. Martín, "Open-switch fault detection in five-phase induction motor drives using model predictive control," IEEE Transactions on Industrial Electronics, vol. 65, no. 4, pp. 3045-3055, 2018.

[7] S.-K. Baek, H.-U. Shin, S.-Y. Kang, C.-S. Park, and K.-B. Lee, "Open fault detection and tolerant control for a five phase inverter driving system," Energies, vol. 9, no. 5, p. 355, 2016.

[8] M. Bermudez, I. Gonzalez-Prieto, F. Barrero, H. Guzman, M. J. Duran, and X. Kestelyn, "Open-phase fault-tolerant direct torque control technique for five-phase induction motor drives," IEEE Transactions on Industrial Electronics, vol. 64, no. 2, pp. 902-911, 2017.

[9] A. Shawier, A. S. Abdel-Khalik, R. A. Hamdy, K. H. Ahmed, and S. Ahmed, "Postfault operation of five-phase induction machine with minimum total losses under single open-phase fault," IEEE Access, vol. 8, pp. 208696-208706, 2020.

[10] L. Schreier, J. Bendl, and M. Chomat, "Analysis of stator and rotor currents and torque of induction machine with rotorbar faults," Electrical Engineering, vol. 103, no. 1, pp. 519-528, 2020.

[11] N. Priyadarshi, S. Padmanaban, M. S. Bhaskar, F. Blaabjerg, and J. B. Holm-Nielsen, "An improved hybrid PV-wind power system with MPPT for water pumping applications," International Transactions on Electrical Energy Systems, vol. 30, no. 2, Article ID e12210, 2020.

[12] K. Lee and Y. Han, "Reactive-power-based robust MTPA control for v/f scalar-controlled induction motor drives," IEEE Transactions on Industrial Electronics, vol. 69, no. 1, 2021.

[13] C. C. Scharlau, L. F. A. Pereira, L. A. Pereira, and S. Haffner, "Performance of a five-phase induction machine with optimized air gap field under open loop V/f control," IEEE Transactions on Energy Conversion, vol. 23, no. 4, pp. 10461056, 2008.

[14] A. Iqbal, E. Levi, M. Jones, and S. N. Vukosavic, "Generalised sinusoidal PWM with harmonic injection for multi-phase VSIs," in Proceedings of the 37th IEEE Power Electronics Specialists Conference, pp. 1-7, Jeju, South Korea, June 2006.

[15] A. S. Morsy, A. S. Abdel-khalik, S. Ahmed, and A. Massoud, "Sensorless $V / f$ control with MRAS speed estimator for a five-phase induction machine under open-circuit phase faults," in Proceedings of the 7th IEEE GCC Conference and Exhibition (GCC), pp. 268-273, Doha, Qatar, November 2013.

[16] A. S. Morsy, A. S. Abdelkhalik, S. Ahmed, and A. M. Massoud, "Sensorless speed control of a five-phase induction machine under open-phase condition," Journal of Engineering, vol. 2014, no. 5, pp. 201-209, 2014.

[17] M. Kutija, D. Sumina, and I. Čolović, "A current limiting technique for $V / f$ controlled induction machines," in Proceedings of the 16th International Power Electronics and Motion Control Conference and Exposition, pp. 1001-1004, Antalya, Turkey, September 2014.

[18] in3-Phase ACIM Scalar ControlSpansion, Sunnyvale, CA, USA, 2015.
[19] inAD5000 Servo DriveBeckhoff Automation GmbH, Verl, Germany, 2020.

[20] inSinamics G120 CU250S-2 Control UnitsSiemens AG, Munich, Germany, 2020.

[21] S. K. Sul, Control of Electric Machine Drive Systems, John Wiley \& Sons, Hoboken, NJ, USA, 1st edition, 2011.

[22] A. Yazdani and R. Iravani, Voltage-Sourced Converters in Power Systems: Modelling, Control and Applictaions, John Wiley \& Sons, Hoboken, NJ, USA, 1st edition, 2010.

[23] K. Kyslan, M. Lacko, Z. Ferkova, and P. Zaskalicky, $V / f$ Control of Five Phase Induction Machine Implemented on DSP Using Simulink CoderELEKTRO, Taormina, Italy, 2020.

[24] A. Smith, S. Gadoue, M. Armstrong, and J. Finch, "Improved method for the scalar control of induction motor drives," IET Electric Power Applications, vol. 7, no. 6, pp. 487-498, 2013.

[25] I. Boldea, Induction Machines Handbook: Steady State Modeling and Performance, CRC Press, Boca Raton, FL, USA, 3rd edition, 2020.

[26] A. Pal and S. Das, "Development of energy efficient scheme for speed sensorless induction motor drive," International Transactions on Electrical Energy Systems, vol. 30, no. 8, Article ID e12448, 2020

[27] A. Gouichiche, A. Safa, A. Chibani, and M. Tadjine, "Global fault-tolerant control approach for vector control of an induction motor," International Transactions on Electrical Energy Systems, vol. 30, no. 8, Article ID e12440, 2020.

[28] M. Janaszek, "Extended clarke transformation for $n$-phase system," Proceedings of Electrotechnical Institute, vol. 63, no. 274, pp. 5-26, 2016.

[29] L. Udut, A. Chernyshev, A. Chernyshev, and I. Chernyshev, "Current limiting in scalar electric drives with induction motors," Science Bulletin of the Novosibirsk State Technical University, vol. 59, no. 2, pp. 120-133, 2015.

[30] M. Rosić, M. Luković, M. Bjekić, and B. Koprivica, "Slip compensation of U/F controlled induction machine through educational laboratory setup," in Proceedings of the International Scientific Conference UNITECH 2018, pp. 16-22, Gabrovo, Bulgaria, November 2018.

[31] M. Hinkkanen, L. Tiitinen, E. Molsa, and L. Harnefors, "On the stability of volts-per-hertz control for induction motors," IEEE Journal of Emerging and Selected Topics in Power Electronics, p. 1, 2021.

[32] C. Mastorocostas, I. Kioskeridis, and N. Margaris, "Thermal and slip effects on rotor time constant in vector controlled induction motor drives," IEEE Transactions on Power Electronics, vol. 21, no. 2, pp. 495-504, 2006.

[33] K. Horváth, M. Kuslits, and S. Lovas, "Model-based control algorithm development of induction machines by using a well-defined model architecture and rapid control prototyping," Electrical Engineering, vol. 102, no. 3, pp. 1103-1116, 2020. 